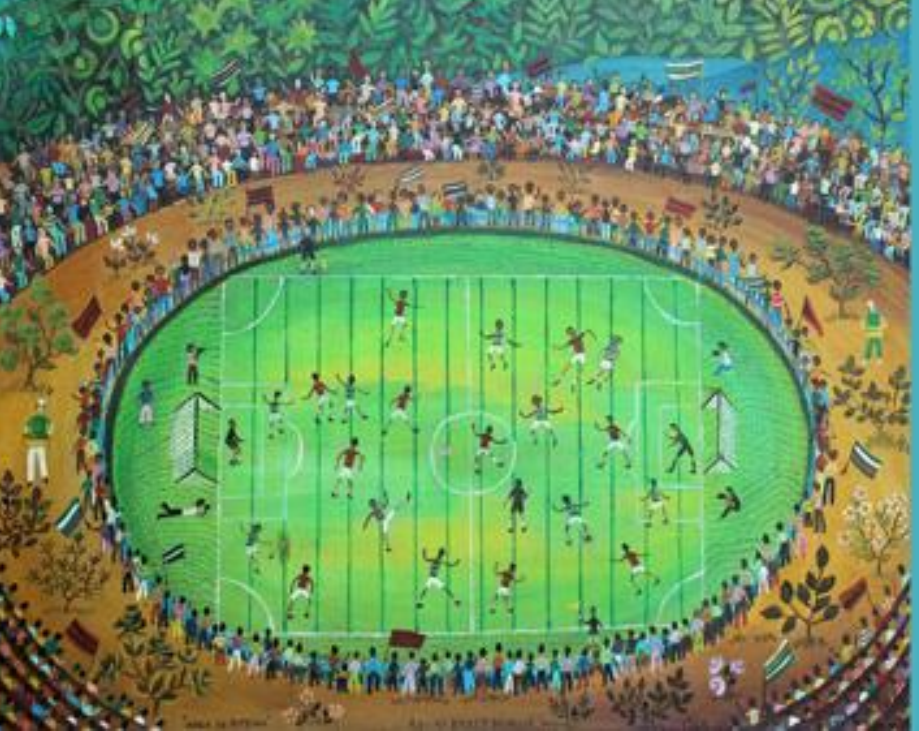

\title{
AMOR QUE DÓI: O PROCESSO DO LUTO NA LETRA DA CANÇÃO “VOLTA”, DE JOHNNY HOOKER
}

\section{LOVE THAT HURTS: THE GRIEVING PROCESS IN THE LYRICS OF "VOLTA", BY JOHNNY HOOKER}

\author{
Pétrus David Sousa PATRICIO \\ UNIVERSIDADE REGIONAL DO CARIRI, Brasil
}

\author{
RESUMO | INDEXAÇÃO | TEXTO | REFERÊNCIAS | CITAR ESTE ARTIGO | O AUTOR \\ RECEBIDO EM 30/06/2018 • APROVADO EM 20/08/2018
}

\section{Resumo}

O amor e seus desdobramentos são temas recorrentes nas produções artísticas, da poesia à pintura, sejam nas cantigas de amor e amigo dos antigos trovadores, peças românticas clássicas de Shakespeare ou em narrativas fílmicas. Tão frequentemente quanto a saudade de um ente querido é, consequentemente, a dor que a acompanha. Levando em consideração a quantidade de produções artísticas que abordam tais temas, pôde-se escolher na música popular brasileira um título que parece se sobressair em diferentes aspectos no plano do conteúdo. Volta, do cantor Johnny Hooker, apresenta um amplo cenário do comportamento humano quando sob o estresse do processo do luto. Utilizando principalmente os estudos de Sigmund Freud e os dados colhidos por Mariana Marcondes, foi possível, interpretando a letra estrofe por estrofe, mostrar como o compositor conseguiu vasculhar a psique e dela extrair informações e sentimentos complexos que se comportam de forma genérica, mas coletiva. Apresentam-se ainda possíveis aberturas linguísticas e teóricas sobre a letra da canção, assim 
como a discussão de práticas e atitudes que funcionariam como um norte para futuras reinterpretações da música.

\begin{abstract}
Love and its unfoldings are recurrent themes in artistic productions, from poetry to painting, be them love or friend songs from the ancient troubadours, classic romantic plays from Shakespeare or filmic narratives. As often as the longing for a loved one is, consequently, the pain that follows it. Taking into account the number of artistic productions that approach such themes, it was possible to choose in brazilian popular music a name that stands out in different aspects in the content level. Volta, by singer Johnny Hooker, presents a broad scenario of the human behavior when under the stress of mourning. Using, mainly, the studies of Sigmund Freud and the data collected by Mariana Marcondes, it was possible, interpreting the lyrics strophe by strophe, to show how the composer managed to search the psyche and to extract information and complex feelings that behave in a generic, but collective way. There are also possible linguistic and theoretical openings on the lyrics, as well as the discussion of practices and attitudes that would function as a north for future reinterpretations of the music.
\end{abstract}

\title{
Entradas para indexação
}

PALAVRAS-CHAVE: Psicanálise. Amor. Luto. Dor. Johnny Hooker. KEYWORDS: Psychoanalysis. Love. Grief. Pain. Johnny Hooker.

Texto integral

[...] Afinal a ausência é também uma morte, a única e importante diferença é a esperança.

(José Saramago)

\section{INTRODUÇÃO}

Parece ser necessário partirmos da ideia de que não existe amor sem desejo, para só então pensarmos a etapa seguinte: se não há amor sem desejo, então o que se é desejado? A resposta para essa pergunta é simples. Foi desenvolvida no imaginário coletivo a ideia de que não somos seres completos em nós mesmos, de que em algum momento do nosso desenvolvimento psíquico (e até mesmo da constituição física), perdemos algo - ou alguém - que nos tornaria inteiros. Ideia essa que busca todo tipo de apoio, como por exemplo no mito dos andróginos, na obra $O$ Banquete, do filósofo grego Platão. Já que a humanidade está incompleta, então o seu desejo só pode ser um: encontrar sua parte há muito perdida, a sua outra metade. 
"Cara metade" ou "a outra metade da laranja" são apenas algumas das metáforas usadas para exemplificar essa falta do outro em nós. Desde os tempos das cantigas trovadorescas de D. Diniz, esse sentimento de perda se faz presente. Ao longo dos períodos e escolas artísticos, com suas produções sobre amores idealizados e inalcançáveis, a concepção de incompletude do ser foi sendo reforçada, além do sentimento de morrer de amor e por amor - vide Shakespeare e sua peça Romeu e Julieta (1597), e a pintura homônima (1886), de Francis Sidney Muschamp, onde a falta é igualmente poderosa e aniquiladora. A sétima arte, o cinema, é bastante prolífica quando o assunto é amor e suas nuanças. Atribuído a ele o status cult, o filme 500 dias com ela (2009), dirigido por Marc Webb, aborda o começo, o desenvolvimento, o fim e a superação do relacionamento entre Summer e Tom, interpretados por Zooey Deschanel e Joseph Gordon-Levitt, respectivamente.

Obras musicais não escapam desse tema. São facilmente apontáveis na música popular brasileira canções onde essa busca por um amor e o sofrimento decorrente desta falta figuram o conteúdo elaborado. Você não me ensinou a te esquecer (1992), da dupla sertaneja Chrystian \& Ralf, inúmeras vezes regravada, ou Segredos (2001), da banda Frejat, são apenas alguns exemplos possíveis. Dentro da música, a organização melódica é responsável por ajustar tons e ritmos no plano da expressão, ou seja, como algo é cantado, a interpretação do artista. 0 presente trabalho se encarrega da segunda organização dentro das canções: o plano do conteúdo, a estruturação do que é dito.

Tendo em vista o sofrimento psíquico vivenciado pelo eu-lírico decorrente do fim de um enlace amoroso (seja por meio de escolha do término ou pela morte do parceiro/da parceira), pretende-se analisar neste artigo como o processo psicossomático do luto por um objeto contribuiu na construção de um sentimento, aparentemente universal, com fins estéticos. Para atingir esse objetivo, foi selecionada a letra da canção Volta (HOOKER, 2015), do pernambucano Johnny Hooker, por conter um relato sucinto sobre as aflições sentidas após o término de um relacionamento hipotético.

Ao escolher essa música como corpus, foi necessário observá-la como um relato em forma de súplica, onde os eventos narrados seguem uma aparente evolução de dor, portanto sendo relacionáveis ao que é estudado dentro da psicanálise como o processo do luto. Hooker, ao desenvolver a música, conseguiu elaborar, consciente ou não sobre os estudos no campo, um panorama amplo do que foi teorizado a respeito do assunto. Dentro desta análise, outros subtemas e investigações a respeito do relacionar-se com alguém serão abordados, tanto para um melhor embasamento teórico como para a abertura de possíveis novas interpretações.

Em um primeiro momento, se faz necessário explicar a dinâmica do amor, segundo a psicanálise: como a libido trabalha na busca e obtenção do prazer do ego e o comportamento deste diante de outrem. Em seguida, passa-se para o foco do artigo propriamente dito: o desaparecimento dessa fonte de prazer e as consequências disto no eu. Como o ser humano se comporta quando alguém que escolheu como objeto de amor não está mais presente? A dor de ainda amar um ser 
que se tornou intangível. Sofrimento este que se expressa tanto no psíquico quanto no físico. Sofrimento que parece ser bastante evidente na música de Hooker.

\title{
1 Observações psicanalíticas sobre o amor e o amar
}

A relação energética (econômica) da libido nas dicotomias eu-objeto, prazer-desprazer e atividade-passividade foi uma das colunas de sustentação dos estudos freudianos durante grande parte de sua obra, portanto é compreensível que ao tratar das questões sobre o amor, ele as também observasse sob esse prisma.

A libido é, inicialmente, a energia que movimenta as relações do indivíduo com o mundo, sendo, segundo Freud, originalmente sexual, e podendo, dependendo do objeto a que se ligue, ter sua natureza reprimida ou posta de lado, ainda que existente. Manoelita Dias dos Santos, de forma concisa e elucidativa, definiu a libido como:

\begin{abstract}
Um termo popularmente associado apenas à sexualidade, no entanto é mais abrangente e constitui toda experiência de prazer e a base de todas as nossas construções. Usamos a libido para nos relacionar com pessoas, com o trabalho e com tudo o que está ao nosso redor. Sendo a libido a força que nos liga mais fortemente à vida, podemos compreender sua importância. Quando investimos essa energia em alguém, ele se torna emocionalmente significativo para nós. (SANTOS, 2018, p. 51).
\end{abstract}

Em Sobre o narcisismo: uma introdução, Freud (1996b) parte da suposição de que as pulsões libidinais originais do ego e do objeto são inicialmente indiscerníveis: quando crianças, quando nossas necessidades básicas são atendidas, sentimos prazer. A essa fase auto-erótica ${ }^{1}$, onde o mundo exterior não é de interesse da criança, onde ela é o centro, dá-se o nome de narcisismo primário. 0 ser humano em todas as suas relações com o mundo e consigo mesmo tende a buscar o prazer ou à eliminação do desprazer. Quando uma criança sente fome (situação de desprazer) e chora, a mãe a alimenta, saciando-a; dessa forma, eliminando o desconforto.

De acordo com Freud, em Os instintos e suas vicissitudes:

Se o objeto se torna uma fonte de sensações agradáveis, estabelece-se uma ânsia (urge) motora que procura trazer o objeto para mais perto do ego e incorporá-lo ao ego. Falamos da 'atração' exercida pelo objeto proporcionador de prazer, e dizemos que 'amamos' esse objeto. (FREUD, 1996c, p. 82). 
A criança quando reconhece o cheiro da mãe e sabe que ali é a sua principal fonte de prazer - seja em questão de alimentação, proteção e higiene -, tende a esticar os braços para que ela a pegue. Quando outra pessoa a segura, às vezes chora e se contorce em busca do colo da mãe. Em Inibições, sintomas e ansiedade, Freud (1996g) fala de sentimentos de ansiedade e dor, os quais a criança passa ao ter medo de que sua mãe tenha sido substituída e/ou tenha desaparecido. É apenas com o desenvolvimento físico e psíquico do ser, que acontece um deslocamento inicial dessas energias: parte da libido é retirada do ego e investida num objeto, formando um novo tipo de ligação.

Esse deslocamento chamado de anaclítico é descrito como uma continuação da fase autoerótica da criança, onde o indivíduo buscará nos primeiros objetos sexuais, a satisfação de suas próprias pulsões autopreservativas. Segundo Freud (1996b, p. 54), "os primeiros objetos sexuais de uma criança são as pessoas que se preocupam com sua alimentação, cuidados e proteção; isto é, no primeiro caso, sua mãe ou quem quer que a substitua". Por isso é tão comum ouvir pensamentos que reforcem a ideia de que procuramos em objetos amorosos, simulacros de nossas figuras maternas e paternas.

Porém:

Não costumamos dizer que amamos os objetos que servem aos interesses da autopreservação; ressaltamos o fato de que necessitamos deles, e talvez expressemos uma espécie de relação adicional diferente para com eles [...]. (FREUD, 1996c, p. 83).

Além da escolha anaclítica, há a escolha de objeto do tipo narcísica. A fonte onde se busca prazer não é mais escolhida tendo a mãe como modelo, mas tendo o próprio eu: procuramos amar o que somos, o que fomos ou o que poderíamos/gostaríamos ser. Freud, então, admite que a principal característica desse segundo tipo de amor é a supervalorização sexual do outro, estado semelhante ao de uma neurose obsessiva, onde resquícios do narcisismo primário são transferidos para esse objeto posterior. Na pessoa apaixonada ocorre um empobrecimento do ego, um efeito de submissão ao objeto amado. Em Psicologia de grupo e análise do ego, é dito que "sua submissão à emoção torna-se extraordinariamente intensificada, enquanto que sua capacidade intelectual é acentuadamente reduzida [...]" (FREUD, 1996f, p. 55-56). 0 indivíduo apaixonado entra num estado parecido ao de um hipnotizado: suas energias libidinais estão sob o comando do hipnotizador, ou seja, daquele ou daquela a quem ele escolheu como objeto amoroso. E mais adiante:

Vemos que o objeto está sendo tratado da mesma maneira que nosso próprio ego, de modo que, quando estamos amando, uma quantidade considerável de libido narcisista transborda para o objeto. Em muitas formas de escolha amorosa, é fato evidente que o objeto serve de sucedâneo para algum inatingido ideal do ego de nós mesmos. Nós o amamos por causa das perfeições que nos 
esforçamos por conseguir para nosso próprio ego e que agora gostaríamos de adquirir, dessa maneira indireta, como meio de satisfazer nosso narcisismo. (FREUD, 1996f, p. 70-71).

Os impulsos narcísicos do ego são deixados de lado numa pessoa que está amando. 0 ego, como foi dito, se torna humilde, obediente ao outro. 0 prazer que antes seria obtido de forma direta, é obtido através da identificação e introjeção com o/do prazer do outro. 0 objeto amado tomou conta do ego. Num caso extremo, até o autoamor é ofuscado. Nádia P. Ferreira, em $A$ teoria do amor na psicanálise, resumiu essa aglutinação brilhantemente: "se o amado for apreendido como se fosse a outra metade [...] espera-se do amor um verdadeiro milagre: a junção de dois seres em um" (FERREIRA, 2004, p. 9). 0 problema dessa união está quando o objeto que agora preenche totalmente o ego é retirado da equação.

\section{$2 \quad$ A dor do fim}

Como já mencionado, num estado de enamoramento, há o superinvestimento da libido num objeto externo. Quando, por algum motivo, esse objeto não se faz mais presente na relação, o caminho dessa energia aplicada é o regresso ao ego, onde ocorre um processamento, para só então ser novamente investida. Segundo Zuanella (2016, p. 74), esse é o "caminho natural à saída do narcisismo inicial [...] não necessariamente se configura numa patologia". Tal retirada não possui tempo definido e depende exclusivamente de cada pessoa. Nesse meio tempo, o sujeito passa por uma série estádios físicos e psíquicos que variam dependendo das circunstâncias (o objeto, a natureza do afastamento). A esse processo é dado o nome de luto.

Zimerman (2001, p. 253) define o luto como o "estado psíquico resultante da perda de alguém muito querido, que pode provocar dor e angústia, num quadro geral de reação depressiva que, para ser superado, necessita daquilo que Freud concebeu como trabalho de luto".

Em Luto e melancolia, fazendo uma comparação com a melancolia (hoje em dia, um estado semelhante ao quadro clínico da depressão), Freud (1996d, p. 142) definiu o luto como "a reação à perda de um ente querido, à perda de alguma abstração que ocupou o lugar de um ente querido, como o país, a liberdade ou o ideal de alguém, e assim por diante". Dessa forma, Freud expande o conceito de luto: estamos acostumados a automaticamente relacionar o luto com o falecimento de um ente, quando, na verdade, é possível ser aplicado à perda de algo não concreto, imaterial, por meio da morte ou de qualquer outra casualidade. Quando nos referimos a um enlace amoroso, falamos do pesar que os ex-parceiros sofrem durante o término. 0 teste de realidade mostra que o companheiro não se encontra mais ao alcance, então as energias investidas devem ser retiradas e retornadas ao ego. Comumente falamos que algumas pessoas superam um fim de um relacionamento mais rápido que outras quando esse processo de luto, subjetivamente, não é longo. 
Marcondes, Trierweiler e Cruz (2006, p. 95-96) introduzem sua pesquisa mostrando que:

\begin{abstract}
Cada separação tem uma história e, quase sempre, provoca um abalo emotivo que, segundo Giusti (1987), na escala das causas de estresse, vem imediatamente após a morte de um parente ou o choque de ser preso, e que pode ser considerado equivalente ao trauma causado pela perda da única fonte de subsistência. Quando o relacionamento se rompe, o trabalho necessário para recuperar o equilíbrio emocional e existencial requer um dispêndio de energia psíquica, e esse dispêndio, frequentemente, provoca deterioração física e nervosa, tal como ocorre durante um luto grave.
\end{abstract}

Todo relacionamento é formado por indivíduos que possuem diferentes formas de ver o mundo e lidar com diferentes situações, portanto o período do luto é relativo, mas, como Freud (1996d, p. 142) afirma: "confiamos em que seja superado após certo lapso de tempo, e julgamos inútil ou mesmo prejudicial qualquer interferência em relação a ele". Sob o olhar econômico da dicotomia prazer-desprazer, é correto afirmar que um indivíduo não abre mão facilmente de uma fonte de prazer tão estimada, principalmente quando esta, como mencionado anteriormente, tomou conta do seu ego. Como enxergar esse processo de imenso desconforto de forma equilibrada? 0 próprio Freud admitiu ter dificuldade para responder essa questão, e ainda parece surpreso ao afirmar que "esse penoso desprazer seja aceito por nós como algo natural" (FREUD, 1996d, p. 143).

Melanie Klein conseguiu achar uma resposta para essa lacuna:

\begin{abstract}
Pode-se dizer que cada etapa do crescimento emocional, intelectual e físico é empregada pelo ego como um meio de superar a posição depressiva. [...] Assim, a dor associada ao lento processo do teste de realidade durante o trabalho do luto parece se explicar em parte pela necessidade não só de renovar os elos com o mundo externo e portanto reviver constantemente a perda, mas também de usar esse processo para reconstruir com agonia o mundo interno, que o indivíduo julga estar em perigo de decair e desmoronar. (KLEIN, 1996, p. 395-397).
\end{abstract}

É um sofrimento necessário. Compreende-se que para melhorar, é preciso passar por todos os momentos ruins da angústia, pois tem-se a esperança de que a dor no futuro não será tão pungente quanto aparenta no momento imediato da perda. 0 ego admite temporariamente o desprazer. Mesmo sendo uma situação dolorosa e penosa para ambos, parece haver uma ideia coletiva de níveis de sofrimento, onde um lado da relação sofre menos que o outro. Marcondes, Trierweiler e Cruz (2006, p. 96) admitem que "dependendo de quem é o responsável pelo término da relação, diferentes tipos de dor são sentidas. Embora 
seja considerado ruim para ambos, costuma sofrer mais aquele que é percebido como deixado". Não é que a separação não doa em ambos, mas "para quem quer separar-se, o que predomina, inicialmente, é o alívio, às vezes a euforia, por se ver livre do peso e da tensão da situação infeliz" (MARCONDES; TRIERWEILER; CRUZ, 2006, p. 96).

Porém, enquanto de um lado temos a sensação de alívio e liberdade, ao outro ficam-se reservados os sentimentos negativos: tristeza, ódio, culpa. Essa dor psíquica é tamanha que o mundo não se faz mais interessante. Pode ocorrer uma intensa vontade de isolamento para que haja uma maior concentração da mente no processo do luto ou como uma forma de desinteresse pelo Outro; às vezes é possível perceber que o enlutado ouve conselhos e/ou condolências de pessoas próximas e não os toma como relevantes. A sua dor é tamanha que uma espécie de cortina de fumaça se cria entre o ego e o mundo, onde o único foco é a imagem do amado fantasma ${ }^{2}$. Freud (1996d, p. 143) observou que "cada uma das lembranças e expectativas isoladas através das quais a libido está vinculada ao objeto é evocada e hipercatexizada [...]". No entanto, segundo Nasio (1997, p. 28), "se o eu ficar assim imobilizado em uma representação coagulada, o luto se eterniza em um estado crônico, que paralisa a vida da pessoa enlutada durante vários anos, ou até durante toda a sua existência".

0 eu fica então dividido entre o amor exacerbado pela efígie do objeto ausente e a prova da realidade que mostra essa perda. A dor nasce justamente daí: ao mesmo tempo que se ama o objeto que ainda é presente no psiquismo de diferentes formas, sabe-se que ele talvez não volte. Segundo Nasio (1997, p. 29), "o que dói, não é perder o ser amado, mas continuar a amá-lo mais do que nunca, mesmo sabendo-o irremediavelmente perdido". O saber que a pessoa amada já não está mais presente causa dor, enquanto o amor e a constante recordação do objeto perdido aplacam a dor. 0 sofrimento é tão profundo que preferimos recusar a ausência do amado; apesar de paradoxal, é isso que parece aplacar a angústia. Esse distanciamento da realidade e superestima à representação psíquica do objeto pode ocasionar episódios semelhantes aos de alucinações. Nesses casos, o enlutado pode admite ouvir a voz do amado em um lugar público (ou até mesmo vê-lo na multidão, quando na verdade, é apenas uma pessoa que possui traços físicos semelhantes), passar por locais onde o amado costuma(va) frequentar na certeza de que ele estará lá. 0 saber ficando em segundo plano, faz com que o amor crie uma nova realidade cheia de fantasias e de delírios.

Após algum tempo, a intensa valorização da imagem do objeto vai desaparecendo e a dor que isso trazia, vai sendo abrandada. Quando as energias psíquicas passam por todo o trabalho do luto de forma saudável, elas estão prontas para serem investidas num novo objeto.

Nasio resume o processo do luto da seguinte forma:

O luto é um longo caminho, que começa com a dor viva da perda de um ser querido e declina com a aceitação serena da realidade do seu desaparecimento e do caráter definitivo da sua ausência. [...] De fato, para conter os efeitos devastadores do trauma, o eu 
percorre, excessivamente carregado de afeto, a representação do ser eleito e desaparecido. Agora, durante o período de luto, o eu percorre o caminho inverso: pouco a pouco, desinveste a representação do amado, até que esta perca a sua vivacidade e deixe de ser um corpo estranho, fonte de dor para o eu. [...] Com o luto, a pessoa enlutada não esquece o morto nem deixa de amá-lo; ela apenas tempera um apego demasiado excessivo e reativo à perda brutal. (NASIO, 1997, p. 63-64).

\section{3 "Saudade, dor que dói demais"}

Em 2013, o diretor Hilton Lacerda lançou Tatuagem. O filme estrelado por Irandhir Santos e Jesuíta Barbosa se passa no Recife, no fim da década de 1970, e narra o romance de Clécio (Irandhir), líder de uma trupe teatral que realiza apresentações de cunho crítico à política e à sociedade, e Fininha (Jesuíta), um jovem militar. De forma crua, sincera e bastante delicada, Lacerda, além de contar o despertar e o desenrolar de um relacionamento, mostra diferentes formas de opressões que esses dois grupos (artistas e homossexuais) sofriam na época do regime militar brasileiro.

A trilha sonora do filme é composta por nomes consagrados da música brasileira como Dalva de Oliveira, Caetano Veloso e Ângela Rô Rô. O pernambucano Johnny Hooker também se juntou a eles cantando Volta, música original para o filme - o cantor fez uma participação no longa cantando-a. Em 2015, Johnny lançou seu primeiro álbum de estúdio chamado Eu vou fazer uma macumba pra te amarrar, maldito! (HOOKER, 2015), do qual Volta é uma das faixas integrantes.

A canção, que não tem relação com o enredo do filme, mostra um eu-lírico em um estado de extrema tristeza, suplicando que seu companheiro/sua companheira volte para junto dele. 0 personagem se encontra no que parece ser os estágios iniciais do luto, onde a imagem psíquica do outro está sendo superinvestida e a dor é intensa.

Informações a respeito dos gêneros ou sexualidade das personagens e da natureza do distanciamento entre eles não são apontadas em nenhum verso, muito provavelmente para que o público consiga se reconhecer na letra, como o cantor disse numa entrevista ao repórter Pedro Bial (WELL WALL, 2018).

A letra, apesar de se assemelhar bastante com o que Freud descreveu como melancolia, se enquadra, de forma ainda mais completa, com o processo do luto, inclusive no abatimento que o eu-lírico expressa logo nos primeiros versos:

Volta

Que o caminho dessa dor me atravessa. 
Marcondes, Trierweiler e Cruz (2006, p. 97) afirmam que quando o eu percebe que o término é definitivo, "costuma vir a depressão, quase sempre acompanhada pelos sentimentos de autodepreciação, pena de si mesmo, baixa autoestima". Iniciar a música com um verbo no imperativo afirmativo representa isso: o eu se pôs numa posição de submissão ao outro, pedindo, suplicando que o objeto amado volte para sua vida. A dor dessa falta é sentida num limiar entre o psíquico e o físico, que "atravessa" o corpo. Essa dor ocorre toda vez que há um deslocamento das energias psíquicas para a imagem do objeto. 0 cheiro de um perfume, uma música, um local, são simples coisas que podem fazer uma pessoa lembrar imediatamente do ente amado, projetando na mente os momentos bons sem volta que aquelas sensações permearam.

Uma das principais características do luto descritas por Freud (1996d, p. 143) é a "perda de interesse pelo mundo externo". 0 eu não vê mais sentido no mundo. Pensar em viver num mundo onde não se tem mais o ser amado é insuportável. Ao mesmo tempo, é difícil não pensar no antigo parceiro. 0 ciúme e o sentimento de posse nascem quando se cogita a ideia de que ele/ela possa estar com outra pessoa; segue-se a frustração por perceber que o eu não faz mais parte da vida do outro. "Às vezes ocorre que, depois da separação, ao mesmo tempo em que se aguça o desejo de possuir e de controlar o outro, acaba-se perdendo toda a motivação para viver e experimenta-se a penosa sensação de estar à deriva" (GIUSTI, 1987 apud MARCONDES; TRIERWEILER; CRUZ, 2006, p. 97). É o que Hooker expressa quando canta:

\author{
Que a vida não mais me interessa \\ Se você vai viver com um outro rapaz \\ $[\ldots]$ \\ Volta \\ Que sem você eu já não posso viver.
}

Toda a libido está investida nesse outro indivíduo. 0 empobrecimento do ego causa o pensamento melancólico de aniquilar a si próprio. A ideia de que o outro já seguiu em frente e conseguiu um novo amor é triste e causa ainda mais pena. 0 prolongamento da imagem psíquica e o amor ainda vivo, podem culminar na ideia de que o indivíduo, além de ser deixado, foi trocado e menosprezado. " $O$ que ele/ela tem que eu não tenho?", é uma das queixas que pode nascer desse sentimento de substituição. A baixa autoestima do ego faz a ligação: aquele a quem amo me trocou, pois eu não fui o suficiente, eu não tinha o necessário para ele se manter ao meu lado.

Em 1919, no ensaio Além do princípio do prazer, Freud (1996e) inaugura a teoria da pulsão de morte. Enquanto a libido e as pulsões autopreservativas estariam a serviço de Eros, a pulsão de morte estaria a serviço de Tanatos. Essa é a pulsão que tende ao fim de tudo, quando catexizada, tende a comportamentos destrutivos. Em Volta, essa pulsão de morte oscila entre voltar-se contra o ego ou 
contra a figura remanescente do objeto amado, portanto, despertando sentimentos que beiram a autoaniquilação e a destruição do Outro.

\author{
Volta \\ Que eu perdoo teus caminhos, teus vícios \\ Que eu volto até o início
}

Te carregando mais uma vez de volta do bar.

Nos versos acima, o eu-lírico se põe na clara posição de submissão de indivíduo apaixonado, que Freud descreve em Psicologia de grupo e análise do ego. Um estado de servidão. Quando desenvolve a analogia de que os estados de uma pessoa enamorada ao de um hipnotizado são semelhantes, afirma que "a relação hipnótica é a devoção ilimitada de alguém enamorado, mas excluída a satisfação sexual [...]" (FREUD, 1996f, p. 72). O eu apaixonado se põe aos serviços e às vontades do eleito como fonte de amor e prazer. Quando Hooker canta que o eulírico perdoará tudo do outro, passará por cima até dos comportamentos ruins e estará lá quando for necessário, ele o fará em nome da saudade e da necessidade do outro, de uma distorcida ideia de amor.

Essa baixa autoestima e necessidade neuróticas, fazem pôr em prova o que Freud chamou, em Além do princípio do prazer, de "compulsão à repetição". Em sua discussão sobre as neuroses de guerra, o autor propõe que no ser humano existe uma tendência à repetição. E vai mais longe: suspendendo o princípio do prazer, o ser humano tende a repetir experiências ruins, por um motivo desconhecido. Laplanche e Pontalis (2001, p. 84) comentam que "com efeito, são experiências manifestamente desagradáveis que são repetidas, e, numa primeira análise, não se vê muito bem que instância do sujeito poderia encontrar satisfação nisso [...]".

Como a tendência à repetição se demonstra em relacionamentos, então? Como a letra da canção mostra: o indivíduo se submete a situações que lhe causam desprazer, na esperança de que um prazer maior lhe será retribuído posteriormente. Esse claro comportamento masoquista havia sido uma grande lacuna na teoria freudiana. Até 1919, o psicanalista não conseguia explicar como tais comportamentos se encaixariam na dicotomia prazer-desprazer. Com a introdução da pulsão de morte, uma luz caiu sobre tais atitudes. Quando a pulsão de morte se volta para o ego, experiências, inicialmente tomadas como desprazerozas, passam a ser experimentadas por outras instâncias do psiquismo de forma prazerosa. Dessa forma, o masoquismo do eu-lírico é compreensível.

Em casos documentados de violência doméstica (MARQUES, 2005), um dos fatores apontáveis que explica o fato de as vítimas continuarem com seus agressores é a crença de que eles irão mudar. Em relacionamentos onde há um constante término-reconciliação, a ideia de que "dessa vez vai ser diferente". A música não fala sobre relacionamentos abusivos, nem faz menções sobre, mas essa abertura poética e teórica faz-nos pensar sobre o assunto: 
[...]

É impossível ter de escolher

Entre teu cheiro e nada mais.

Há um óbvio dilema vivido pelo personagem. 0 ego está esquartejado, toda sua libido parece flutuar sem conseguir voltar totalmente para si, aguardando. Os pensamentos conflitivos refletem uma brecha: ao ter que decidir entre o objeto amado e o resto do mundo, o eu pode optar por continuar no sofrimento de uma esperança ou pode optar por seguir em frente com o trabalho do luto e encarar a talvez dolorosa ideia de que, quando completado, o amado não fará mais parte de sua vida. Como uma interpretação do eu na canção mostra um ego totalmente esvaziado, tomado por uma extrema tristeza e uma submissão masoquista, a primeira opção é a mais consonante com o restante dos versos:

\author{
Volta \\ Me diz que o nosso amor não é uma mentira \\ E que você ainda precisa \\ Mais uma vez se desculpar.
}

Essa é uma estrofe que mais levanta questões do que as elucida. Seria uma possível extensão do sentimento de substituição quando o eu-lírico pede uma resposta sobre a veracidade do amor entre eles? 0 autoconceito negativo, a possibilidade tão real de o outro ter seguido em frente, podem fazer nascer a dúvida de que talvez o relacionamento com a protagonista do sofrimento tenha sido apenas algo momentâneo, que talvez os afetos trocados não tenham sido verdadeiros. Será que as juras de amor trocadas foram apenas meios para fins carnais? A insegurança sendo alimentada parece ser o foco dessa estrofe da canção. 0 que é essa necessidade de receber desculpas do outro? Estaria aqui indicações sobre a possível causa do término desse relacionamento?

\author{
Então procurei \\ Nos bares da Aurora me lamentei \\ E confesso que talvez joguei \\ Tuas fotos e discos no mar.
}

Essa estrofe é bastante significativa, pois mostra uma sequência de evolução do luto: da depressão (um estado de extrema tristeza) para a raiva. 0 eu chora e fala de sua angústia pelos bares da cidade. A imagem da bebida alcóolica aqui é importante, já que o enlutado pode usar a bebida como uma forma de atenuar sua dor. Em contrapartida, pode tê-la intensificada. 0 álcool pode ajudar a liberar os 
pensamentos que o indivíduo tentou manter apenas para si, a raiva reprimida. Comportamentos viciosos ou autodestrutivos como a ingestão de bebidas alcoólicas, com a finalidade de aplacar uma dor e retirar sossego daí, estão relacionados à pulsão de morte.

Em Os instintos e suas vicissitudes, Freud (1996c, p. 84) afirma que "se uma relação de amor com um dado objeto for rompida, frequentemente o ódio surgirá em seu lugar, de modo que temos a impressão de uma transformação do amor em ódio". 0 ódio, como é explicitado no ensaio, anda lado a lado com o amor e pode ser expresso na forma de agressividade e/ou destruição. Diz-se que o ódio é despertado quando um desejo pulsional não é atendido. Dessa forma, é possível explicar a ambivalência de sentimentos humanos onde, ao mesmo tempo que amamos um objeto, o detestamos.

Como afirmam Marcondes, Trierweiler e Cruz (2006, p. 96):

Os sentimentos de ódio e frieza, nessas horas, surgem para suavizar ou neutralizar os sentimentos de pesar e de culpa, que talvez doam muito mais. Pensar com raiva só nas coisas ruins anestesia a dor de lamentar o que não deu certo. Em meio ao ódio, ao ressentimento e à dor, vem a tendência a denegrir, difamar e rebaixar o ex-parceiro para convencer-se de que não perdeu grande coisa.

Destruir os símbolos desse amor doloroso é uma das formas de expurgar o sofrimento. 0 problema ao lidar com esse tipo de raiva, segundo Elizabeth KüblerRoss (1969, p. 44), é que "essa raiva é deslocada em todas as direções e projetada no ambiente em momentos quase aleatórios" ${ }^{3}$. 0 amor é deixado de lado e o ódio toma a frente. A pulsões agressivas são postas, mais uma vez, no centro do palco:

\author{
Então procurei \\ Pelo teu cheiro nas ruas que andei \\ Nos corpos dos homens que amei \\ Tentando em vão te encontrar.
}

Uma das descrições sobre o trabalho do luto dada por Freud (1996d, p. 143) é "perda da capacidade de adotar um novo objeto de amor (o que significaria substituí-lo) e o mesmo afastamento de toda e qualquer atividade que não esteja ligada a pensamentos sobre ele". De fato, quando o mundo se torna pobre, é difícil encontrar nele algo ou alguém que possa substituir a marca profunda que o amado eleito deixou. Em Contribuições à psicologia do amor II, é dito que os objetos de desejo seguintes são apenas uma imitação dos anteriores ou originais (FREUD, 1996a). Quando esse objeto primeiro se perde, "ele se representa, frequentemente, por uma sucessão infindável de objetos substitutos, nenhum dos quais, no entanto, proporciona satisfação completa" (Freud, 1996a, p. 114). Segundo Ferreira (2004, 
p. 13-14), "é nesse sentido que Lacan afirma que o desejo é sempre o mesmo, que está sempre se deslocando de um objeto para outro. Em relação ao objeto nunca é isto [....] Aqui entra em cena a invenção do amor com a finalidade de suprir a falta".

A tentativa de deslocamento da libido não se completa. 0 ser amado ainda está tão presente que na busca de novos objetos sexuais, tenta-se achar reminiscências dele que mais serviriam como placebos para a dor psíquica do eu. 0 eu-lírico tenta montar um monstro de Frankenstein simbólico com as partes da pessoa amada que achar semelhantes nos outros parceiros sexuais que tiver ao longo do luto ou da vida. Mas, novamente, a prova da realidade é devastadora e mostra que ter partes que se assemelham ao objeto original não é tê-lo, de fato.

\section{CONSIDERAÇÕES FINAIS}

O amor, esse sentimento universal, aparentemente fonte de tanto prazer para os indivíduos que decidem se unir num enlace amoroso, mostra-se também fonte de dessabores. A busca incessante por essa "cara metade" que faz os loucos se jogarem de cabeça numa fonte incerta. A constante substituição dos vazios que fazem as pessoas se submeterem a situações desconfortantes em busca de uma vaga ideia de completude. Segundo Ferreira (2004, p. 10):

\footnotetext{
Amar coloca em cena dois lugares: sujeito (amante) e objeto (amado). Aquele sobre o qual se abate a experiência de que alguma coisa falta, mesmo não sabendo o que é, ocupa o lugar de amante. Aquele que, mesmo não sabendo o que tem, sabe que tem alguma coisa que o torna especial, ocupa o lugar de amado. 0 paradoxo do amor reside no fato de que o que falta ao amante é precisamente o que o amado também não tem. 0 que falta? 0 objeto do desejo.
}

Será que o que achamos encontrar no outro existe somente nele? As tendências narcísicas são totalmente suprimidas, o autoamor é esquecido em função desse objeto de amor secundário que nos promete sensações de conforto. Segundo Freud (1996c, p. 82), "poderíamos, num caso de emergência, dizer que um instinto 'ama' um objeto no sentido do qual ele luta por propósito de satisfação [...]". O amor é uma constante luta pelo prazer, porém permeada por picos angustiantes.

Esse enlace amoroso aparentemente belo, uma hora chega ao fim. Seja por meio da morte ou por uma simples escolha unilateral. 0 término é a única certeza. E aqueles que ficam sofrem, suplicam, pranteiam e aniquilam por causa da dor. Essa dor que consome, essa dor que se inicia no psíquico e culmina no somático. Nasio (1997, p. 25) afirma que "a ruptura de um laço amoroso provoca um estado de choque semelhante àquele que é induzido por uma violenta agressão física". 
A arte, como uma forma de reflexo e expressão do mundo, nunca deixou - $\mathrm{e}$ é certo que nunca deixará - de abordar e questionar tais pensamentos. Johnny Hooker é apenas um dos nomes em todo esse meio, mas o seu entendimento da psique humana parece ser tão profundo que é impossível deixar de registrar Volta como esse estudo da densidade da alma e dos tormentos humanos. A canção progride lentamente, mas de forma harmônica com o que é pretendido pelo compositor, num estilo abrasileirado de cabaret. A exploração das diferentes situações de aflições do eu-lírico em nome desse amor que partiu é bela por ser tão real, assim como dura e coletiva pelo mesmo motivo. A análise dessa letra, em específico, permitiu explorar inúmeras situações do cotidiano que se relacionam com as abordagens do amor e da saudade, mostrando a habilidade de criação do artista em congruência ao que foi pensado a respeito dos assuntos. A abordagem deste artigo é apenas uma das possíveis, inclusive dentro do próprio tema do luto.

\section{Notas}

${ }^{1} \mathrm{O}$ termo "erótico" quando se tratando de Freud não deve ser entendido obrigatoriamente no sentido sexual. O Eros a que o psicanalista de refere diz respeito ao prazer, podendo ele ser de natureza sexual ou não.

2 O termo "amado fantasma" é empregado por Nasio, inspirado no termo clínico "membro fantasma".

3 "[...] this anger is displaced in all directions and projected onto the environment at times almost at random" (tradução livre).

\section{Referências}

FERREIRA, Nadia. A teoria do amor na psicanálise. Rio de Janeiro: Jorge Zahar Ed., 2004.

FREUD, Sigmund. Sobre a tendência universal à depreciação na esfera do amor (Contribuições à psicologia do amor II). Rio de Janeiro: Imago, 1996a. (Edição Standard Brasileira das Obras Completas de Sigmund Freud, 11).

FREUD, Sigmund. Sobre o narcisismo: uma introdução. Rio de Janeiro: Imago, 1996b. (Edição Standard Brasileira das Obras Completas de Sigmund Freud, 14).

FREUD, Sigmund. Os instintos e suas vicissitudes. Rio de Janeiro: Imago, 1996c. (Edição Standard Brasileira das Obras Completas de Sigmund Freud, 14).

FREUD, Sigmund. Luto e melancolia. Rio de Janeiro: Imago, 1996d. (Edição Standard Brasileira das Obras Completas de Sigmund Freud, 14).

FREUD, Sigmund. Além do princípio do prazer. Rio de Janeiro: Imago, 1996e. (Edição Standard Brasileira das Obras Completas de Sigmund Freud, 18).

FREUD, Sigmund. Psicologia de grupo e análise do ego. Rio de Janeiro: Imago, 1996f. (Edição Standard Brasileira das Obras Completas de Sigmund Freud, 18). 
FREUD, Sigmund. Inibições, sintomas e ansiedade. Os instintos e suas vicissitudes. Rio de Janeiro: Imago, 1996g. (Edição Standard Brasileira das Obras Completas de Sigmund Freud, 20).

HOOKER, Johnny. Volta. Eu vou fazer uma macumba pra te amarrar, maldito! Jdm Music, 2015.

HOOKER, Johnny. Volta. Disponível em: <https://www.vagalume.com.br/johnnyhooker/volta.html>. Acesso em: 25 jun. 2018.

KLEIN, Melanie. O luto e suas relações com os estados maníaco-depressivos (1940). In:

Amor, culpa e reparação e outros trabalhos (1921-1945). Rio de Janeiro: Imago, 1996. p. 385412.

KÜBLER-ROSS, Elisabeth. On death and dying. New York: Scribner, 1969.

LAPLANCHE, J.; PONTALIS, J. B. Vocabulário da psicanálise. São Paulo: Martins Fontes, 2001.

MARCONDES, Mariana Valença; TRIERWEILER, Michele; CRUZ, Roberto Moraes. Sentimentos predominantes após o término de um relacionamento amoroso. Psicologia: Ciência $e$ Profissão, Brasília, v. 26, n. 1, p. 94-105, 2006.

MARQUES, Tânia Mendonça. Violência conjugal: um estudo sobre a permanência da mulher em relacionamentos abusivos. 2005. 303 f. Dissertação (Mestrado em Psicologia) Universidade Federal de Uberlândia, Uberlândia, 2005.

NASIO, J.-D. O livro da dor e do amor. Rio de Janeiro: Jorge Zahar Ed., 1997.

SANTOS, Manoelita Dias dos. A lógica da emoção: da psicanálise à física quântica. Disponível em: <http://lelivros.love/book/download-a-logica-da-emocao-manoelita-dias-dos-santos/>. Acesso em: 23 jun. 2018.

WELL WALL. Johnny Hooker no Conversa com Bial. Disponível em: <https://www.youtube.com/watch?v=woCF8RX_wDs>. Acesso em: 27 jun. 2018

ZIMERMAN, David E. Vocabulário contemporâneo de psicanálise. Porto Alegre: Artmed, 2001.

ZUANELLA, Ana Cláudia. Os caminhos da paixão amorosa e alguns de seus destinos patológicos. 2016. 127 f. Dissertação (Mestrado em Psicologia Clínica) - Universidade Católica de Pernambuco, Recife, 2016.

Para citar este artigo

PATRICIO, Pétrus David Sousa. Amor que dói: o processo do luto na letra da canção Volta, de Johnny Hooker. Miguilim - Revista Eletrônica do Netlli, Crato, v. 7, n. 2, p. 522-537, maio-ago. 2018.

\section{0 autor}

Pétrus David Sousa Patricio é graduando do curso de Letras, com habilitação em Inglês, pela Universidade Regional do Cariri (URCA). Desenvolve pesquisas nas áreas de Literatura e Psicanálise, Literatura Gótica/de Horror e Cinema. 